STAIF Conference on Space Exploration Technology,

Albuquerque NM, Feb. 11-15, 2001

\title{
Searching for Life: the Case for Halobacteria on Mars
}

\author{
Geoffrey A. Landis \\ NASA John Glenn Research Center, mailstop 302-1, 21000 Brookpark Road, Cleveland, OH 44135 \\ (216) 433-2238 e-mail: geoffrey.landis@grc.nasa.gov
}

\begin{abstract}
A major objective for NASA exploration of Mars is to determine whether life has existed on Mars in the past, and whether such life on Mars may persist to the present day. On Earth, life exists in all niches in which water exists in liquid form for at least a portion of the year. On Mars, any liquid water would have to be a highly concentrated brine solution. It is likely, therefore, that any present-day Martian microorganisms would be similar to terrestrial halophiles.
\end{abstract}

\section{INTRODUCTION}

Mars is the only planet with surface conditions even remotely similar to those of the Earth. A major objective for NASA exploration of Mars is to determine whether life has existed on Mars in the past, and whether such life on Mars may persist to the present day.

The theme for exploration of Mars is to "follow the water." On Earth, life exists in a range of extreme environments from the dry valleys of Antarctica to the deep interior of the Earth and the boiling springs of Yellowstone. The only criteria for an ecological niche which supports life is that water must be present in liquid form for some portion of the year (Huntress, 1998). To search for life, then, the strategy is to search for the conditions that will allow liquid water.

\section{CONDITIONS FOR WATER ON MARS}

The surface environment of Mars contains water in the form of polar ices, permafrost, and small amounts of atmospheric water vapor. However, it has often been stated (e.g., Malin and Edgett, 2000) that liquid water cannot present on Mars because the atmospheric pressure is at or below the triple-point vapor pressure of water. However, this statement is not strictly correct.

Not all locations on Mars have a pressure below the 6.1 mbar triple-point pressure of water. Both of the Viking spacecraft and also the Pathfinder lander measured surface pressures, and none of these measurements fell below 6.1 mbar. At these locations, and at lower elevation locations on Mars, as the temperature increases above $0 \mathrm{C}$ pure water will exist in a liquidus phase between ice and vapor.

The planet Mars is colder than the Earth, but at many locations daytime surface temperatures rise well above freezing. In particular, surface materials warmed by sunlight can quickly rise above $0 \mathrm{C}$. While liquid water would freeze during the nighttime at every spot on Mars, it is quite possible for transient liquid water to exist during the day.

Also, any present-day water on Mars would be strongly saline. Saline solutions have a low vapor pressure compared to pure water, as well as a lower freezing point. For example, by saturating an aqueous solution with potassium carbonate $\left(\mathrm{K}_{2} \mathrm{CO}_{3}\right)$, the freezing point can be taken to as low as $-37 \mathrm{C}$. Solutions of a mixture of salts can 
have freezing temperatures as low as $-63 \mathrm{C}$ (Brass, 1980). Last, capillary-pore effects mean that water trapped in micron-scale pores between grains of Martian sand would have even lower freezing point than free water.

These effects all add qualifications to the common statement that liquid water cannot be present on the surface of Mars. While indeed it is true that liquid lakes may not exist on the surface, a transient presence of liquid water is possible at many Martian surface locations.

\section{SALT-TOLERANT LIFE ON MARS}

As well as the scarcity of liquid water, adverse conditions on Mars include a surface oxidant and ultraviolet radiation.

One terrestrial form of life that could be an analog for Martian life forms are the halophile ("salt-loving") bacteria (Stoeckenius, 1976; Armstrong, 1981; Armstrong, 1982). Halobacteria such as Halobacterium halobium thrive in highly-concentrated salt solution, and survive desiccation in crystals of solid salt, returning to active life when the salt again liquefies. Dried inside salt crystals, they blow thousands of miles in the formowindblown dust and salt, and by this means colonize transient small pools high concentration brine (Armstrong, 1981; Armstrong, 1982; Vreeland, Rosenzweig, and Powers, 2000). Another species which could be a terrestrial analogue for Martian life is the "desert varnish" (Dorn, and Oberlander, 1981), which can utilize transient occurrences of extremely small amounts of water to maintain metabolism in a normally-dry environment.

Rather than chlorophyll, halobacteria use a photosynthetic molecule bacteriorhodopsin, chemically related to vitamin $\mathrm{A}$, which directly produces chemical energy for metabolism from sunlight without manufacturing oxygen byproduct (Stoeckenius, 1976). It is this photosynthetic pigment which colors halobacteria a striking red.

A salt crust of salt will moderate the environmental ultraviolet. The combination of a salt crust and a UV-blocking pigment (Larsen, 1967) will serve as barriers to allow halobacteria to survive the destructive effect of the ultraviolet environment of Mars.

\section{CONSIDERATIONS FOR FUTURE SCIENCE MISSIONS}

An important goal for science is to determine whether water in the liquid phase occurs on Mars, and at what spots. Based on photographs from the Mars Global Surveyor Spacecraft, Malin and Edgett (2000) believe that they have found evidence for liquid flow (presumably water) on Mars. An example of this evidence is shown in figure 1, acquired by the Mars Global Surveyor (MGS) Mars Orbiter Camera in May 2000, which shows numerous examples of Martian gullies or run-off channels on the same trough-face. All of the channels start in a specific layer, roughly a hundred meters beneath the surface of Mars. These features are located on the south-facing wall of a trough in the Gorgonum Chaos region, an area found to have many examples of gullies proposed to have formed by seepage and runoff of liquid water in recent Martian times.

It would be useful to find whether lowland areas also have liquid water. One possible investigation is by radar. The high electrical conductivity of brine might make it possible to estimate the saline concentration of the liquid. Since the liquid phase is liable to be transient, an orbital mission seeking liquid water needs to remain in orbit for several years, and to visits the same sites at different seasons, to determine the times at which water is liquid.

A search for life could be done directly using spectroscopy. Halobacteria would be indicated by the spectral signature of bacteriorhodopsin. It is unknown whether putative Mars bacteria would utilize the identical pigment, but if so, hyperspectral imaging could be used to find the locations with halobacteria, focusing particularly on flat areas that are likely salt beds. Another high-priority search would be to look for the spectral signature of evaporite salt deposits, to identify "playa" locations where transient lakes might form.

Possible life in the form of halobacteria on Mars lends some suggestions toward landing site choice. A surface lander to search for halobacteria would preferably be targeted toward salt flats, dry lake sites, and the terminal pool of the outflow channels such as those shown in figure 1 . Such sites are also the target locations for other biological investigations, and several such potential biology sites have been identified on Mars. 
Finally, the possible presence of extant life on Mars changes the strategy for eventual human exploration. Even in the best of circumstances, the evidence for life may be subtle. It may be impossible to find evidence of Mars life if we must first identify and discard Earth-generated organic contamination from life support effluvia. Planetary protection has to be done from the start--if we ignore it on the first missions, it will be too late.

If the possibility of present-day life exists on Mars, planetary protection cannot be underemphasized. If stringent planetary protection procedures aren't followed, we may never be able to determine what portion of life on Mars is native, 'and what portion is terrestrial contamination. It will be important to show that there isn't already life on Mars before we propose landing there with living organisms. Operation of a Mars rover by remote control ("telerobotics") directly from Earth is difficult due to the long time delay. However, astronauts on a flyby mission (for initial missions) or an orbital mission (for later missions) could for several days control a rover landed separately with little time-lag. It would provide fully-interactive virtual presence at Mars; the human geologists and biologists could operate in real-time on the surface of the planet, rather than uploading instructions each night for the following day's operation (Landis, 1995). Therefore: telerobotics is suggested as an excellent way to start a program of human Mars exploration.

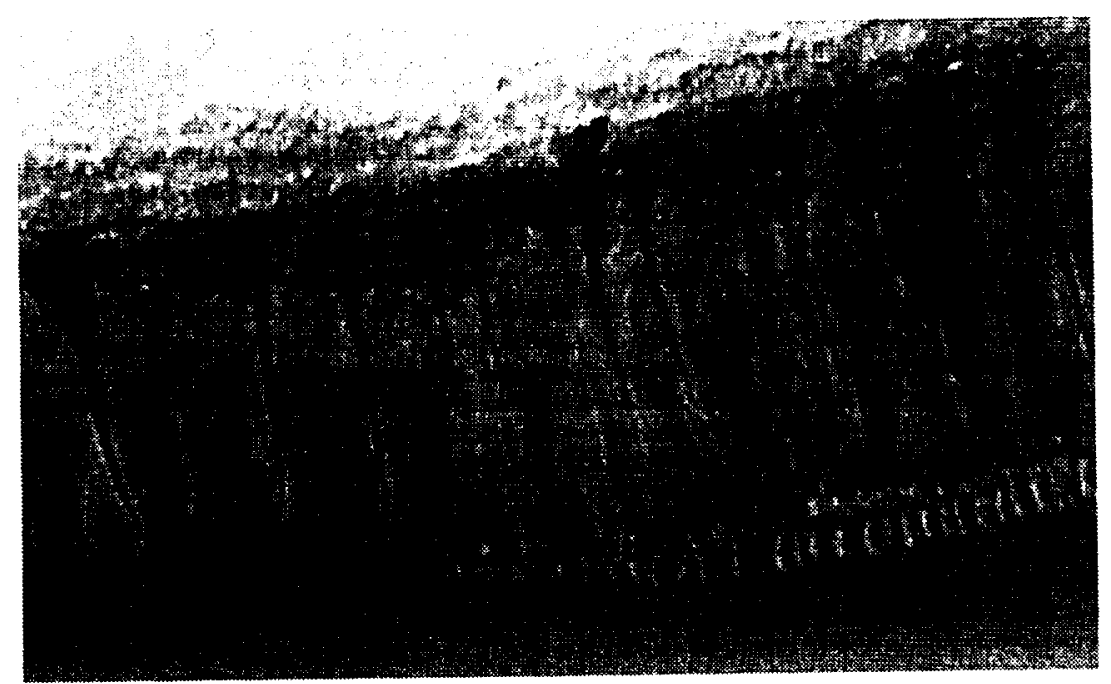

FIGURE 1. "Weeping" Layer in Gorgonum Chaos

While the dark tone of the alcoves and channels in this image is not likely to be the result of wet ground (the contrast in this image has been enhanced), it does suggest that water has seeped out of the ground and moved down the slope quite recently. (Mars Global Surveyor MOC Release No. MOC2-235, 22 June 2000. Image Credit: NASA/JPL/Malin Space Science Systems.)

\section{CONCLUSIONS}

Because of the low temperatures and atmospheric pressure ambient, near-surface liquid water on Mars must be a highly concentrated brine solution. Therefore, if (hypothetical) microorganisms existing on Mars are similar to terrestrial microorganisms, they are likely to be similar to terrestrial halophiles.

\section{REFERENCES}

Armstrong, W.P., "The Pink Playas of Owens Valley," Fremontia 9, 3-10 (1981).

Armstrong, W.P., "Dangeardinella: In Every Drop of Brine," Environment Southwest, Number 499, 18-19 (1982)

Brass, G.W., "Stability of Brines on Mars," Icarus Vol. 42, 20-28 (1980).

Dom, R.I. and Oberlander, T.M., "Microbial Origin of Desert Vamish," Science 213, 1245-1247 (1981).

Huntress, W., quoted The San Diego Union-Tribune, p-A1, Feb. 191998. 
Landis, G., "Footsteps to Mars: an Incremental Approach to Mars Exploration," J. British Interplanetary Society, Vol. 48, $367-$ 342 (1995). Reprinted in From Imagination to Reality: Mars Exploration Studies, AAS Science and Technology Series Volume 91, R. Zubrin, ed., 339-350 (1997).

Larsen, H., "Biochemical Aspects of Extreme Halophilism," Advances in Microbial Physiology, Vol. 1, 97-132 (1967).

Laurin, T.C., "Optical Materials: Transmission and Refractive Index," in Photonics Handbook, Volume 3 (37th edition), Laurin Publishing, Pittsfield MA, 1991, pp. H-295-299.

Malin, M., and Edgett, K., "Evidence for Recent Groundwater Seepage and Surface Runoff on Mars," Science, Vol. 288, 2330$2335(2000)$

Stoeckenius, W., "The Purple Membrane of Salt-Loving Bacteria," Scientific American 234, 38-46 (1976).

Vreeland, R., Rosenzweig, W., and Powers, D., "Isolation of a 250 Million-year-old Halotolerant Bacterium from a Primary Salt Crystal," Nature 407, $897-900(2000)$. 